NASA Technical Memorandum 104554

\title{
Thermal Conductance of Two Interface Materials and Their Applications in Space Systems
}

J.J. Scialdone, C.H. Clatterbuck, and J.L. Wall

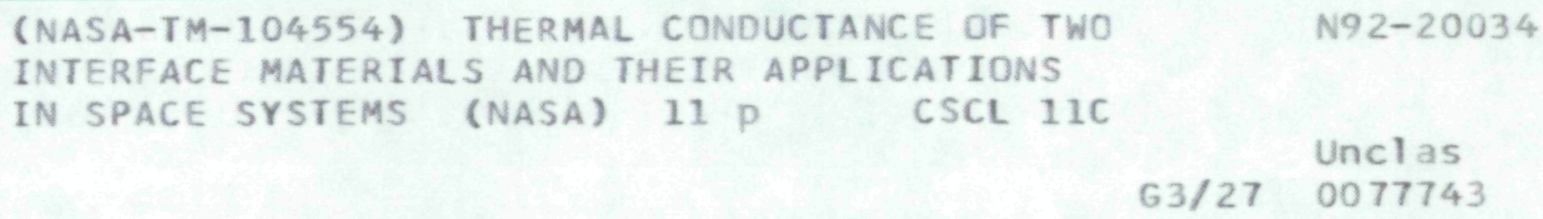

March 1992 
NASA Technical Memorandum 104554

\section{Thermal Conductance of Two Interface Materials and Their Applications in Space Systems}

J.J. Scialdone, C.H. Clatterbuck, and J.L. Wall Goddard Space Flight Center Greenbelt, Maryland

\section{NASA}

National Aeronautics and Space Administration

Goddard Space Flight Center Greenbelt, MD 
The temperature control of spacecraft and instrument systems and subsystems requires heattransfer interface materials that possess appropriate thermal and structural characteristics, in addition to many other properties, to respond to the unique vacuum environment of space. These materials must be easy to apply to, and remove from, the surfaces where they are applied, and must be able to withstand power dissipation extremes, and be used for different clamping configurations and pressures. Silicone-based greases, used in the past, tend to migrate and to contaminate nearby surfaces. Bare metal-to-metal contact offers low thermal conductance and difficulties in estimating the actual heat transfer. Several polymeric materials containing different thermal conductive compounds and structural reinforcements have been prepared to overcome grease and metals problems.

Two polymeric materials have been evaluated: the Cho-Therm 1671 elastomer, manufactured by Chomeric, Inc.; and the CV-2946, a conductive RTV silicone manufactured by McGhan Nusil. Tests have been carried out to learn more about these products: one test configuration was a tightly bolted application; the other test configuration attempted to simulate heat dissipation from a modular power system of a spacecraft. Both were conducted in vacuum and in air, for many clamping pressures, power densities, and as a function of time.

Results indicate that the tightly bolted, torqued fixtures (nearly uniform clamping pressure) did not buckle or distort, and provided optimum thermal conductance. The fixtures simulating actual spacecraft configuration (with sizeable unbolted portions) suffered severe bowing and separating. This caused considerable degradation of conductance values.

The CV-2946 thermal conductance after 24 hours in vacuum was $0.62 \mathrm{~W} / \mathrm{cm}^{2}{ }^{\circ} \mathrm{C}\left(4 \mathrm{~W} / \mathrm{in}^{2}{ }^{\circ} \mathrm{C}\right)$ when clamped with an average pressure of about $350 \mathrm{psi}$, and including a 0.5 -mil Teflon sheet for ease of separation after unbolting. The Cho-Therm 1671 maximum conductance was found to be $4.3 \mathrm{~W} / \mathrm{in}^{2}$ ${ }^{\circ} \mathrm{C}$ when the clamping pressure was about $200 \mathrm{psi}$. After 72 hours in vacuum, the conductance reaches a steady $3.4 \mathrm{~W} / \mathrm{in}^{2}{ }^{\circ} \mathrm{C}$, independent of clamping pressure.

In comparison, the CV-2946 provides higher conductances in air and in vacuum and is less affected by the clamping pressures than the Cho-Therm 1671. However, application of the CV-2946 is laborious, involving compound preparation, application, and curing, as well as the inclusion of a Teflon sheet as an interface if subsequent separation is required.

It has been found that for optimal thermal conductance, candidate interface materials should be subject to uniform pressure over all surface areas. Bolt location, numbers, sizes, and uniformity of applied torques will be important considerations in space systems.

\section{Introduction}

$\mathrm{T}$ he temperature control of power generating systems, of energy storage systems, of power control and distribution systems, of instrument modules and of spacecraft compartments, all require heat-transfer interface materials that possess appropriate thermal conductivities, structural integrity, vibration absorbing properties, electromagnetic compatibilities, noncontaminating properties, and that are easy to apply and remove from the surfaces where installed. The thermal properties of these materials must be known for application under normal environmental conditions, for long- term exposure to the vacuum of space and as a function of clamping pressures, power dissipation extremes, and different clamping configurations. In the past, silicone greases which are easily applied, economical, and meet most of the requirements, have been used. A major shortcoming of grease is its property to migrate on the surfaces because of their low surface tensions. This migration may result in contamination of nearby surfaces and systems.

The silicone-based greases have been reported to provide thermal conductances of about $0.36 \mathrm{~W} / \mathrm{in}^{2}{ }^{\circ} \mathrm{C}\left(5.68 \times 10^{-2} \mathrm{~W} /\right.$ $\mathrm{cm}^{2}{ }^{\circ} \mathrm{C}$ ). These conductance values have been used for the 
design of spacecraft modular power systems ${ }^{1}$. Also, bare metal is reported by the same reference to provide conductance of about $9.16 \times 10^{-2} \mathrm{~W} / \mathrm{in}^{2}{ }^{\circ} \mathrm{C}\left(1.42 \times 10^{-2} \mathrm{~W} / \mathrm{cm}^{2}{ }^{\circ} \mathrm{C}\right)$; i.e., 25 percent of that of the grease. The low conductance of the bare metal joints reflects the contact losses produced by the metal asperities, the metal distortion, and the hot spots developed by irregularities and distortions in those surfaces. For metal joints, it is, in fact, difficult to estimate the conductance and the heat transfer because of those unknown surface properties.

Several polymeric materials containing different thermal conductive compounds and structural reinforcements have been prepared to overcome the grease and metals problems. Two of them-Cho-Therm 1671 elastomer, a product of Chomerics, Inc. ${ }^{2,3}$ and the CV-2946 conductive silicone, a product of McGhan Nusil (NUSIL) ${ }^{4}$, are evaluated here. These two products have relatively good conductivity, low outgassing, good applicability attributes and good structural and thermal properties. The thermal properties of these materials, given in terms of conductivity or conductance, are given by the manufacturers for certain ranges of applied power densities, for a range of applied bolt torques or clamping pressures, and for small ideal configurations. These specifications do not reflect certain aerospace applications that require larger power dissipations, higher applied clamping pressures, large interface configurations, and unusual bolting arrangements. The effect of the vacuum exposure and of the environment, on the thermal properties is also not known in many cases, and so is not identified in manufacturers' specs.

Tests have been carried out, as shown here, to resolve and learn more about the properties of these two materials under different applications. Two configurations have been used. One configuration simulates an application consisting of two 1/2-in-thick, 5 -in $\times 5$-in plates, with one plate made of aluminum ( $\mathrm{Al}$ ) and the other made of copper $(\mathrm{Cu})$, bolted

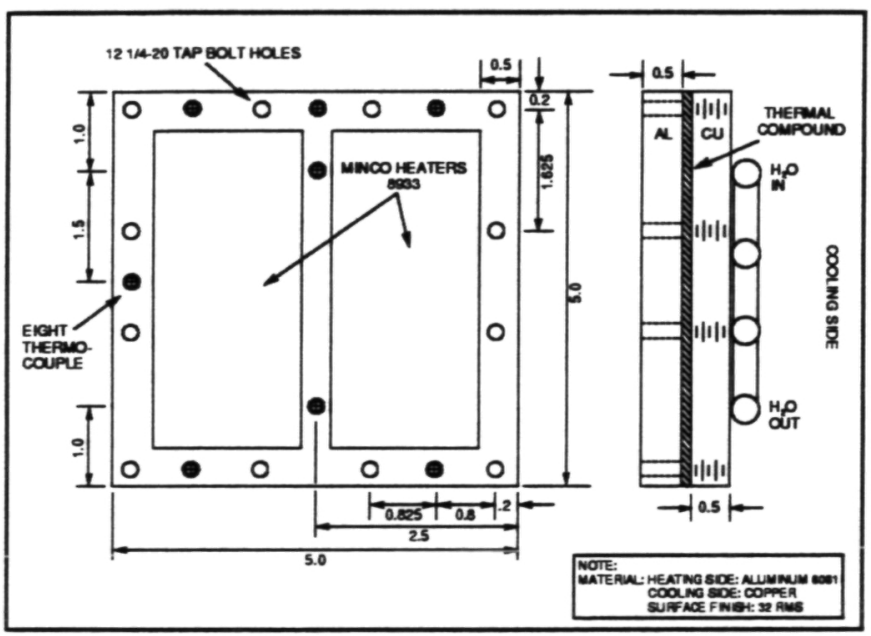

Fig. 1. Thermal plate assembly (5.0 inches $\mathbf{x} 5.0$ inches). Dimensions in inches.

together along the four sides with a total of 12 hex-head, 1/420 bolts (Fig. 1). The other configuration, which simulates a spacecraft modular power system, consists of two anodized $81 / 2$-in $\times 10$-in plates, with one 5/8-in-thick plate made of
7075 aluminum simulating the compartment bolting surface that dissipates energy, and the other, a 0.190-in-thick 7075 Aluminum plate for the energy input. The assembly is bolted along the 10-in-long sides with a total of 10 hex-head, 10-32 bolts screwed into helicoils (Fig. 2). The conductance tests were carried out using torques producing average clamping pressures varying from a low average of $30 \mathrm{psi}$ for the large assembly to a 700-psi average for the small assembly. The power densities were varied from $1 \mathrm{~W} / \mathrm{in}^{2}$ to $4 \mathrm{~W} / \mathrm{in}^{2}$, corresponding to dissipating power of 25 and 100 watts for the $5 \mathrm{x}$ 5 -in assembly, and from 1 to $7 \mathrm{~W} / \mathrm{in}^{2}$, corresponding to 85 to 595 watts for the $8.5 \times 10$-in assembly. The thermal conductances for each of these conditions of power and pressure were measured at ambient conditions, and after 24 and 72 hours in a vacuum of about $10^{-5}$ torr.

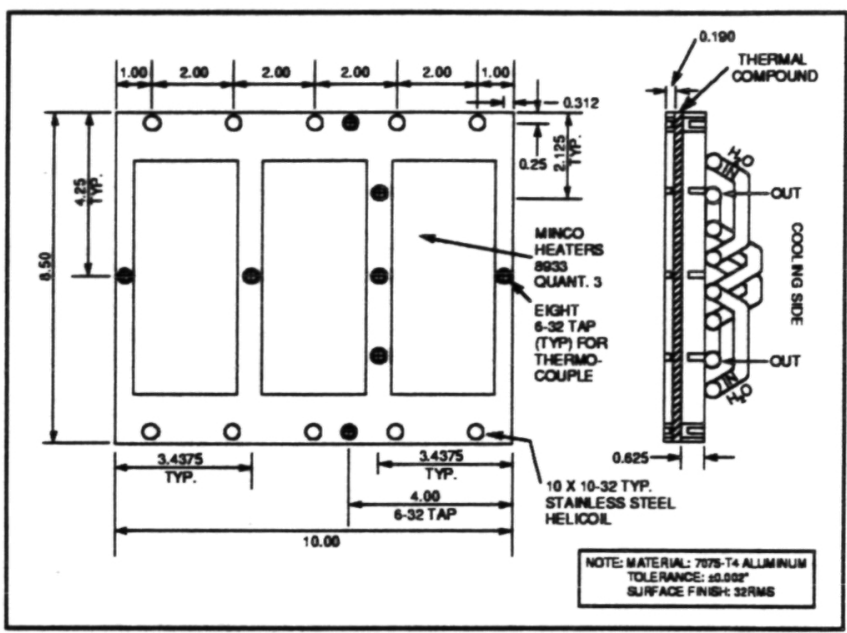

Fig. 2. Thermal plate assembly (8.5 inches $x 10.0$ inches). Dimensions in inches.

The effects of plates bowing under bolting pressures and subsequent relaxation of pressures on the interface materials at certain assembly locations have been noted, together with the degradation of conductances that they produce. Also, optimal average clamping pressures and corresponding torque requirements have been discussed.

\section{Evaluated Interface Materials}

The two thermal interface materials tested were ChoTherm 1671 and McGhan Nusil CV-2946. The Cho-Therm 1671 is manufactured by Chomerics, Inc., a subsidiary of the Grace Company. It is a silicone-reinforced fiberglass containing Boron Nitride, which is rated at $4000 \mathrm{~V}$ for voltage breakdown, has low outgassing $(0.76 \%$ TML, $0.07 \%$ $\mathrm{CVCM})$, and a volume resistivity of $10 \times 10^{14}(\Omega-\mathrm{cm})$. The Cho-Therm is usable at temperatures between -60 to $200^{\circ} \mathrm{C}$, has a specific gravity of 1.55 , a tensile strength of $1000 \mathrm{psi}$, and a tear strength of $100 \mathrm{lb} / \mathrm{in}^{2}$. The thickness of ChoTherm used in these tests is $0.015 \pm 0.002$ in. The range of thermal conductance for this is given as $4.5-5.5 \mathrm{~W} / \mathrm{in}^{2} /{ }^{\circ} \mathrm{C}^{2,3}$. A plot of compression force per unit area vs. strain has been obtained and is shown in Fig. 3. This indicates that the material becomes very hard to compress when the strain is 


\section{ORIGINAL PAGE \\ BLACK AND WHITE PHOTOGRAFH}

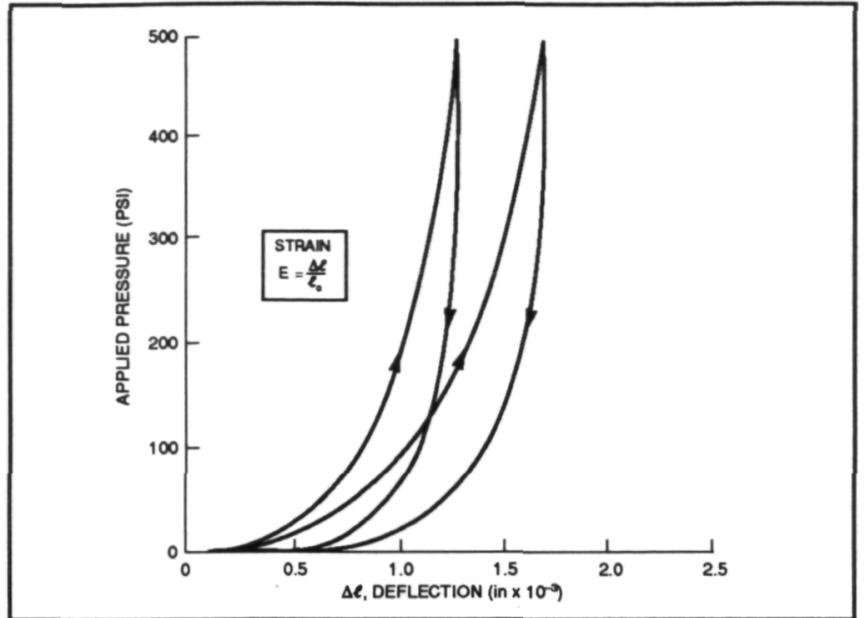

Fig. 3. Pressure vs. Deflection: Cho-Therm 1671, $\ell_{\mathrm{o}}=1.6 \times 10^{-2}$ in Nom.

about $6 \%$, corresponding to a compressive pressure of 200 psi. Two stress vs. strain plots have been shown on the same graph and exhibit the range of possible values. The hysteresy loop of the material is also shown by the plot.

The CV-2946 is a product of McGhan-Nusil Corporation ${ }^{4}$. According to the manufacturer, it is a two-part, white thermal conductive RTV silicone formulated to cure at ambient temperature. It contains as filler Boron Nitride. It is a low outgasser $(0.07 \%$ TML and $0.01 \%$ CVCM) and is usable between temperatures of -65 to $204{ }^{\circ} \mathrm{C}$. It is prepared by stirring a base material with a curing agent using a ratio of 15 parts of base to 1 part of curing agent. The mixture is prepared prior to use and is vacuum deaerated for 2 to 5 minutes to remove air entrapments. The given properties are: specific gravity of 1.5 , tensile strength of $200 \mathrm{psi}$, elongation of $50 \%$, and thermal conductivity of $90 \times 10^{-4}\left(\mathrm{~W} / \mathrm{cm} /{ }^{\circ} \mathrm{C}\right)$. It is also specified that the material has a tack-free time of 24 hours, with full cure achieved after 7 days. The McGhan-Nusil used in the present tests was mixed and then spread on the surface to a thickness of about $25 \times 10^{-3} \mathrm{in}$, and/or $50 \times 10^{-3} \mathrm{in}$, and then allowed to cure for 3-5 days. When using it, a Teflon sheet of 1/2-mil thickness is normally included as an interface between the Nusil and the other metal plate. This prevents the breaking up of the Nusil and provides for easy separation of the plates when the two plates must be separated. Tests without the inclusion of the Teflon sheet were also carried out.

\section{Test Configurations}

Two test configurations were employed for the evaluation of these two materials: one to represent a tightly bolted application, and the other to simulate a common application to dissipate heat from a spacecraft modular power system. The uniformly bolted configuration consisted of two $5 \times 5$ in rigid plates, as shown in Fig. 1. Both plates were $1 / 2$ in thick, one made of $\mathrm{Al}$ and the other made of $\mathrm{Cu}$. The finish was $32 \mathrm{rms}$. The two plates were bolted together with twelve 1/4-20 hex-head bolts evenly distributed along the four sides. The Al plate was provided with two power heaters

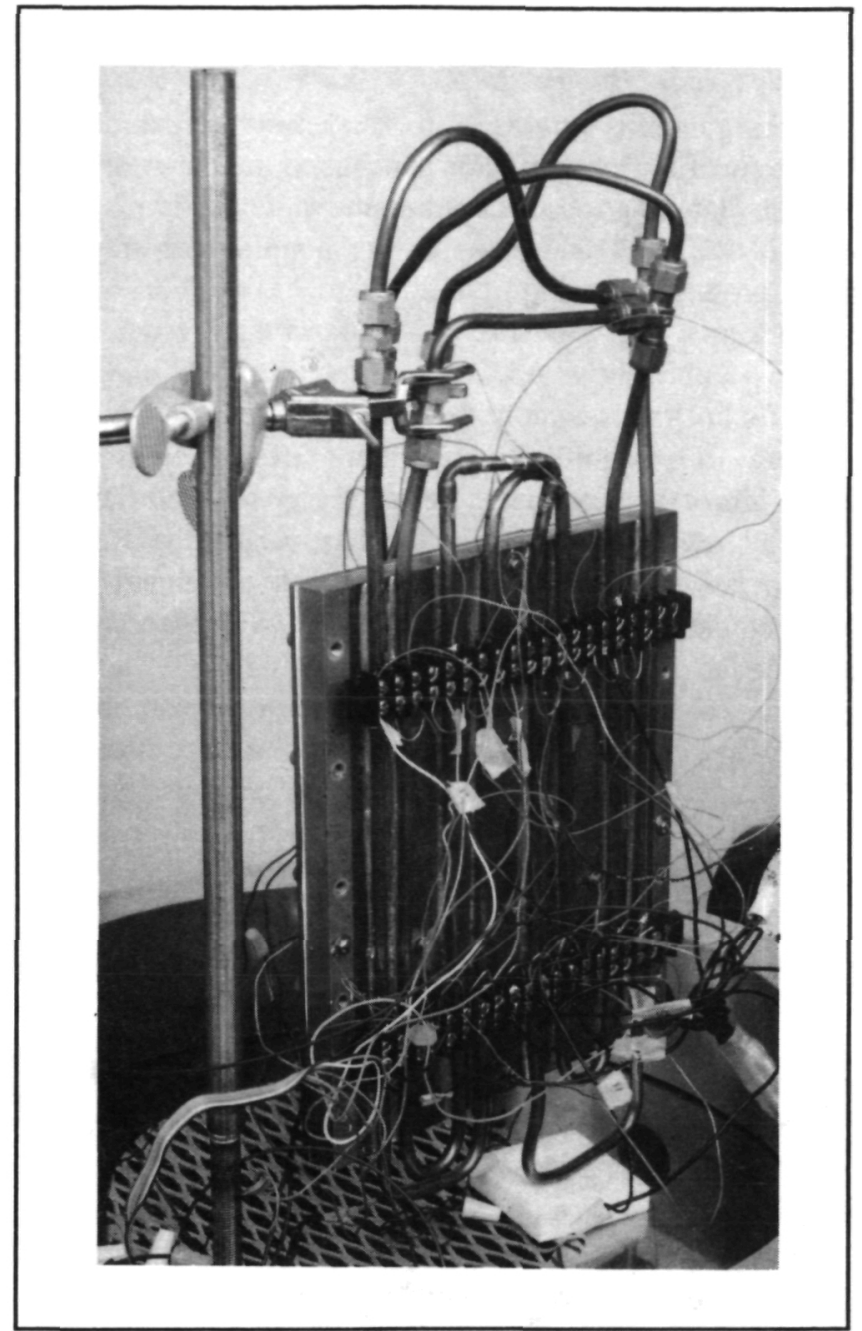

Fig. 4. 8.5-in x 10-in Assembly.

(Minco 8933 HR 5422R 104L12B) attached with 3M Y-966 acrylic adhesive, and the $\mathrm{Cu}$ plate was provided with watercooling copper tubing. Eight sets of thermocouples, located as shown in Fig. 2, were used to indicate the temperatures of the $\mathrm{Al}$ and $\mathrm{Cu}$ plates. Average clamping pressures varying from 100 to 700 psi were produced with bolt torques varying from 15 to $70 \mathrm{in} \mathrm{lb}$. The other configuration consisted of two $81 / 2 \times 10$-in 7075T-4 aluminum plates, as shown in Fig. 2. The plate with attached cooling copper tubing was 0.625 in thick, while the other heating plate with two heater strips was 0.190 in thick. Eight thermocouple sets were provided and located as shown. A total of ten 10-32 stainless-steel bolts, which screw into helicoils, were provided. They were uniformly located in sets of five along the 10-in sides only. No bolts were provided along the $81 / 2$-in sides. The complete assembly is shown in Fig. 4. As will be explained later, this bolting and size configuration resulted in considerable bowing of the 0.19 -in plate when tightly bolted along the two long sides. The deficiency of this configuration in comparison with rigid $5 \times 5$ configuration is evident by the contour plots for both systems. 


\section{Procedure}

The configurations were tested in a vacuum system pumped by a mechanical and by a diffusion pump using an $\mathrm{LN}^{2}$-cooled baffle. The clamping torques holding the materials in place were $15,20,25,40,60$ and 70 in lb, corresponding to average clamping pressures varying from $20 \mathrm{psi}$ to $700 \mathrm{psi}$. For each clamping torque and exposure ( 24 hours in air, 24 and 72 hours in vacuum), the temperature differentials $(\Delta \mathrm{T})$ were obtained for each power-input density $(2,3,4,5,6$ and $7 \mathrm{~W} /$ $i^{2}$ ). The resulting stabilized temperature differentials from the eight pairs of thermocouples were averaged for each of the power densities. The resulting power density over the averaged temperature differential (W/A $\Delta \mathrm{T})$ was then summed for all of the employed power densities and their averages were taken to be the thermal conductance of the material. Those values have been plotted as a function of torques (clamping pressures) and exposures. The averaged $\Delta \mathrm{T}$ vs. the power densities for each exposure and clamping pressure also have been plotted to show the effect of the power input on the conductance, as illustrated by the slope of the plotted curves.

The measurements were made without consideration of the radiation and convection losses under the assumption that those would be negligible based on the relatively low temperature $\left(30^{\circ} \mathrm{C}\right.$ maximum for the $5 \times 5$-in assembly and $\sim 70$ ${ }^{\circ} \mathrm{C}$ maximum for the $81 / 2 \times 10$-in assembly) radiating to the environment and that the convection losses would be eliminated during the vacuum tests. To confirm these hypotheses, a complete set of tests in air was carried out with the assembly completely and firmly insulated with a 1-in-thick Eccofoam encapsulant cap. The results indicated that the changes in conductance amounted to less than 2 percent throughout the ranges of power and pressure.

The thermal conductances of the two materials have been shown as a function of input power densities and of the exposure condition; i.e., if in air or in vacuum for several hours. The thermal conductance, $\mathrm{W} / \mathrm{A} \Delta \mathrm{T}$, is an unidirectional steady-state rate of heat flow, watts per unit area $\mathrm{A}\left(\mathrm{cm}^{2}\right)$, and per-unit temperature drop $\Delta \mathrm{T}\left({ }^{\circ} \mathrm{C}\right)$ across the material of thickness $\ell(\mathrm{cm})$. It is obtained from the Fourier heat conduction equation: $\mathrm{W} / \mathrm{A}=\mathrm{k} \Delta \mathrm{T} / \ell$ rearranged to provide the conductance in terms of the conductivity of the material $\mathrm{k}\left(\mathrm{W} / \mathrm{cm}^{2}\right.$ $\mathrm{K} / \mathrm{cm})$ and material thickness $\ell(\mathrm{cm})$; i.e., W/A $\Delta \mathrm{T}=\mathrm{k} / \boldsymbol{\ell}(\mathrm{W} /$ $\mathrm{cm}^{2} \mathrm{~K}$ ). The inverse of this expression, $\ell / \mathrm{k}=\mathrm{A} \Delta \mathrm{T} / \mathrm{W}$, is the impedance of the material to heat flow. In these tests, where the clamping pressures are changed by the applied torques, the conductance changes reflect the variation in thickness and changes in material density, the filling up of asperities in the materials, and other physical changes in the spacing between the adjacent surfaces of the interface material and the plates. The average clamping pressures have been estimated using the relation $P=T n / 0.15 \mathrm{Ad},\left(\mathrm{N} / \mathrm{m}^{2}\right)$, where $\mathrm{T}(\mathrm{Nm})$ is the applied torque, $\mathrm{n}$ is the number of bolts having an average thread diameter $\mathrm{d}(\mathrm{m})$, and $\mathrm{A}\left(\mathrm{m}^{2}\right)$ is the bolt-clamped surface area. The experimental coefficient 0.15 reflects both the thread and the lubrication of the thread. Rechecking of the bolt torques was done $18 \mathrm{hrs}$ after the initial applied torques

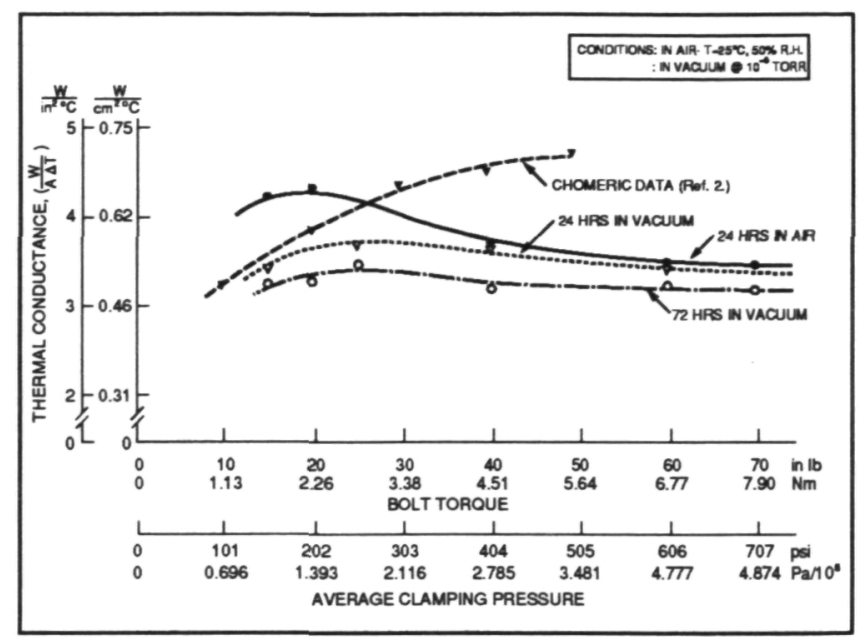

Fig. 5. Thermal conductance of Cho-Therm 1671 (0.016 in-nom. thick) within two 1/2-in-thick 5-in x 5-in plates, bolted with twelve 1/4-in bolts.

at ambient conditions. Fresh material was used for each test at different torques.

\section{Test Results}

Cho-Therm-The results using the $5-\mathrm{x} 5$-in plate assembly are shown in figs. 5 and 6 . Figure 5 shows the thermal conductance vs. average clamping pressure produced by the applied bolt torques as a function of the environmental

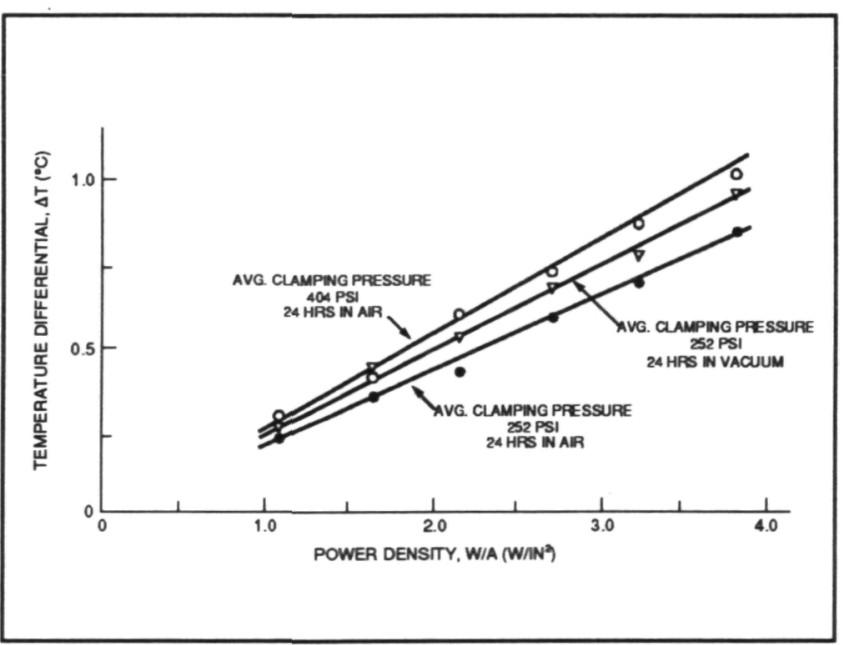

Fig. 6. 5-in x 5-in plate assembly: Cho-Therm 1671 interface material.

exposure of the assembly. The measurements were made with the system exposed to the ambient temperature of about 20 ${ }^{\circ} \mathrm{C}, 40-50$ percent $\mathrm{RH}$ for 24 hours, and in a vacuum of about $10^{-5}$ torr for periods of 24 hours and 72 hours. The range of power density varied from 1 to $4 \mathrm{~W} / \mathrm{in}^{2}$, corresponding to total power input to the plates of 25 and 100 watts. The $\Delta \mathrm{Ts}$ measured vs. power densities are shown in Fig. 6 . The plots show that maximum conductance is obtained when the applied clamping pressure is in the range of $200 \mathrm{psi}$. This is in agreement with the plot of stress vs. strain shown in Fig. 3. That plot indicates that for those ranges of pressures, the 


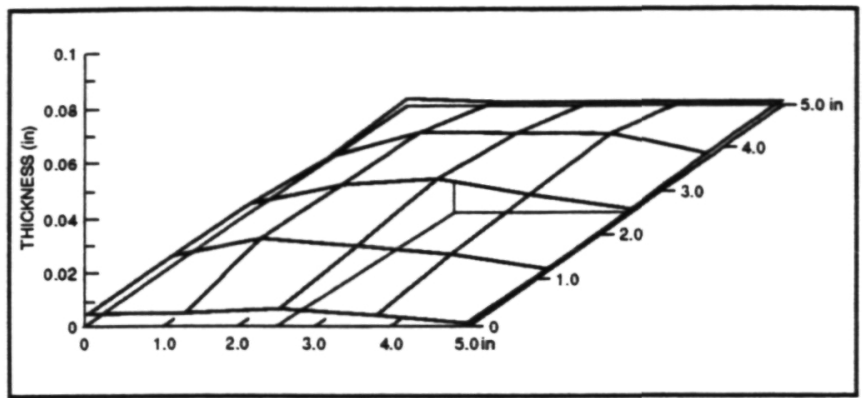

Fig. 7. Thickness map of McGhan Nusil CV-2946 applied to a thickness of 0.025 in and clamped in the 5-in $\times 5$-in plate assembly with bolts torqued to 40 in $\mathbf{~ l b ~ ( 4 0 4 ~ p s i ~}$ avg. pressure).

material is quasi-incompressible. The drop in conductance beyond those pressures to a value of about $3.5 \mathrm{~W} / \mathrm{in}^{2}{ }^{\circ} \mathrm{C}$ from the maximum of $4.3 \mathrm{~W} / \mathrm{in}^{2}{ }^{\circ} \mathrm{C}$ indicates a deterioration of the material and/or a separation at the center of the assembly between the thermal material and the plates. The plate bowing is shown in Fig. 7, which illustrates the contour thickness vs.

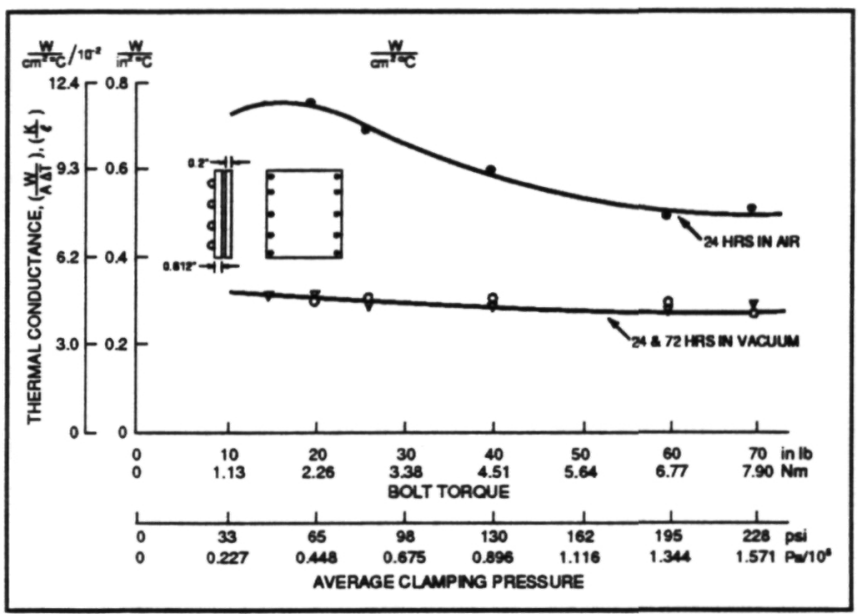

Fig. 8. Thermal conductance of Cho-Therm 1671 (0.016 in nom.) within two 8.5-in $\times 10$-in aluminum plates, bolted along the 10-in sides with a total of ten 10-32 screws in helicoils.

plate location. The measurements in Fig. 7 are those made for the McGhan Nusil application rather than the Cho-Therm, but the effect of torquing is the same.

The effect of vacuum exposure up to 72 hours is also shown in Fig. 5. The conductance drops about 25 percent at the optimum clamping pressure and about 6 percent at high pressure due to vacuum exposure. On the same plot (Fig. 5), the data provided by the manufacturer on conductance (impedance $)^{2,3}$ are shown. Figure 6 plots $\Delta T$ vs. power densities with the environmental exposure and pressure as parameters. It shows the linearity of the conductance in the range of applied power density as represented by the curve slope.

The thermal conductance obtained for the Cho-Therm held between the $81 / 2$-x 10 -in plates bolted on two sides with ten 10-32 screws in helicoils is shown in Fig. 8. The conductance in air is maximum for an average pressure between 50 and $60 \mathrm{psi}$. Its value is $0.75 \mathrm{~W} / \mathrm{in}^{2}{ }^{\circ} \mathrm{C}$, dropping continuously to about $0.52 \mathrm{~W} / \mathrm{in}^{2}{ }^{\circ} \mathrm{C}$ when the bolting pressure is about 228 psi. This considerable degradation in comparison with the values obtained from the $5-\mathrm{x} 5$-in assembly $\left(4.3 \mathrm{~W} / \mathrm{in}^{2}{ }^{\circ} \mathrm{C}\right)$ reflects this particular assembly. In this application, the clamping is done only along the two 10 -in sides leaving an unbolted span of about 8 inches for the other sides. Figure 9 shows the buckling of that plate and the spacing that developed between the plate and the Cho-Therm along the 8-in span as a function of the applied torques. As shown in Fig. 8,

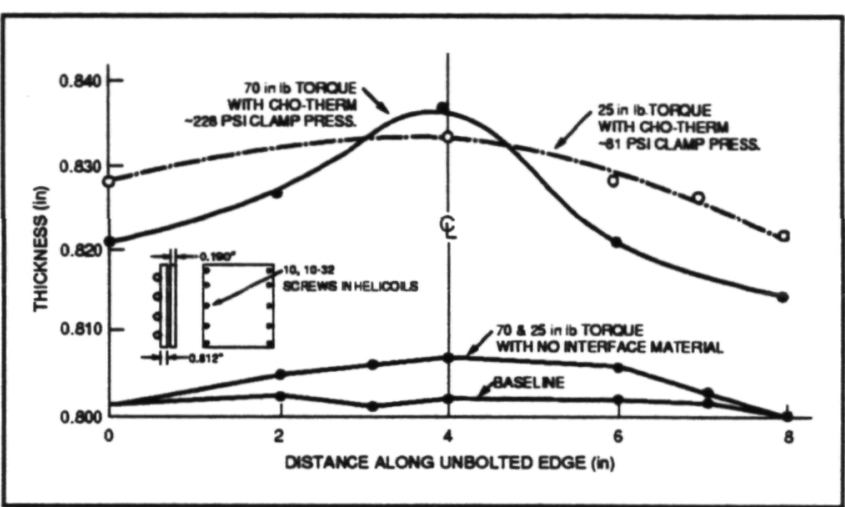

Fig. 9. 8.5-in $\times 10$-in plate assembly buckling with and without the 0.016-in nom. thickness Cho-Therm 1671 vs. bolt torques and average clamping pressures.

the maximum conductance occurs at an average pressure of $50 \mathrm{psi}$. If one assumes that most of the pressure provided by the bolts is applied along the two 10-in sides and for a width of about 1 inch from the edge, the $50 \mathrm{psi}$ is equivalent to (50 $\times 81 / 2 \times 10) /(2 \times 10 \times 1)=212 \mathrm{psi}$, which reflects approximately the pressure at which the conductance is maximum, as found for the 5-in x 5-in assembly. Further drop in the conductance from torque is evident by the increased buckling at the center of the plate. At 228-psi average (70-in lb torque)

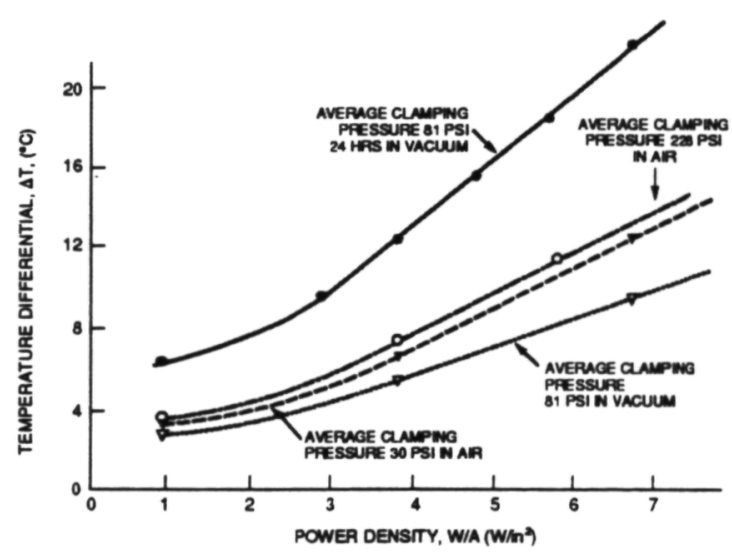

Fig. 10. 8.5-in x 10-in plate assembly: Cho-Therm 1671 (0.016 in nom.) interface material.

the difference between the bolting locations and the center of the plates is about 0.016 in, as shown in Fig. 9, which is the void or space along the 8-in span causing about a 44-percent loss of conductance. The conductance after 24 and 72 hours in vacuum is about $0.3 \mathrm{~W} / \mathrm{in}^{2}{ }^{\circ} \mathrm{C}$, or about 50 percent of that 


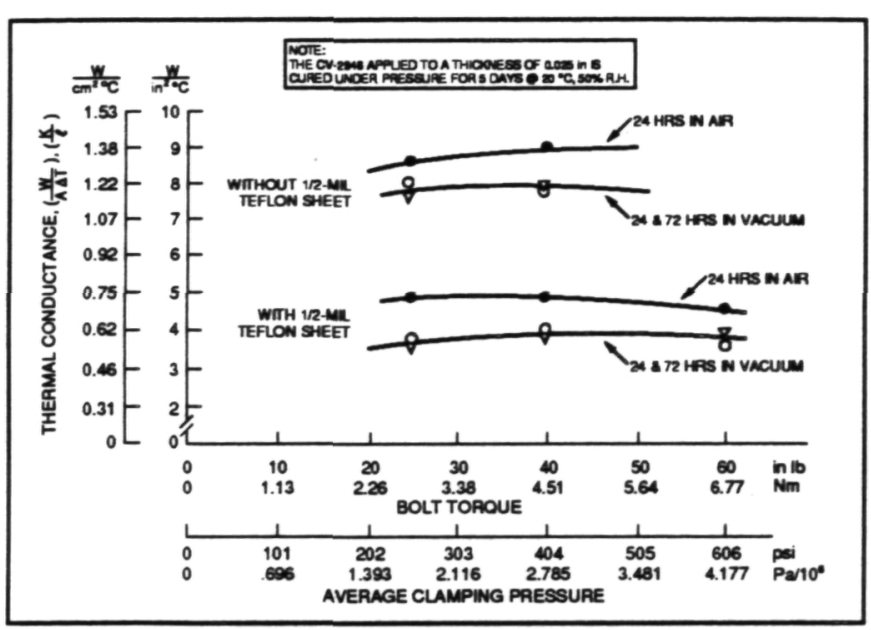

Fig. 11. Thermal conductance of McGhan Nusil CV2946 within two 1/2-in thick, 5 -in $\times 5$-in plates bolted with twelve 1/4-in bolts, with and without a 0.0005 -in-thick Teflon sheet included for separation.

at ambient pressure. The proportionality of the conductance versus the power-density input is shown in Fig. 10. It shows that the direct relation is not valid below $2 \mathrm{~W} / \mathrm{in}^{2}$.

McGhan-Nusit- The thermal conductance of this material as obtained using the arrangement with the two 5-in x 5-in metal plates sufficiently clamped along the four sides, is shown in Fig. 11. The results show that the conductance remains quasi-constant as the pressure is increased between

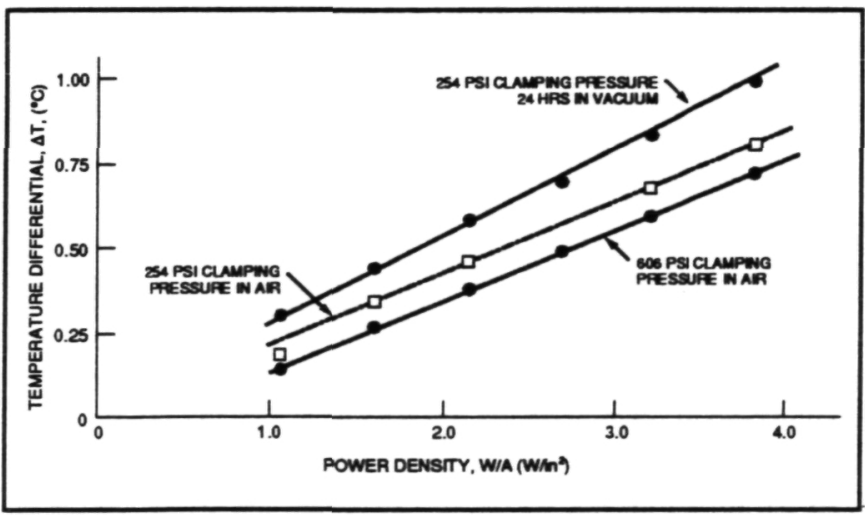

Fig. 12. 5-in x 5-in plate assembly: McGhan Nusil CV-2946, $\ell=0.025$ with a 0.0005 -in-thick Teflon sheet.

200 and $700 \mathrm{psi}$, both for the measurements in air and in vacuum. The degradation in vacuum stops after 24 hours (the value after 72 hours is the same as that for 24 hours). The conductance for the normal thickness of 0.025 in, with the 0.0005 -in-thick Teflon film as used here, is about $5 \mathrm{~W} / \mathrm{in}^{2}{ }^{\circ} \mathrm{C}$ in air, and after exposure to vacuum it is about $4 \mathrm{~W} / \mathrm{in}^{2}{ }^{\circ} \mathrm{C}$, indicating a 20-percent degradation. The material is only minimally affected by the bolting-induced pressure.

The effect of varying the input power between 1 and $4 \mathrm{~W} /$ in $^{2}$ is shown in Fig. 12 for the array using the Teflon sheet. It shows that the conductance remains constant between those power inputs. Results of tests carried out with the same material but without the 0.5 -mil Teflon sheet, which is employed for ease of plate separation upon plate disassembly,

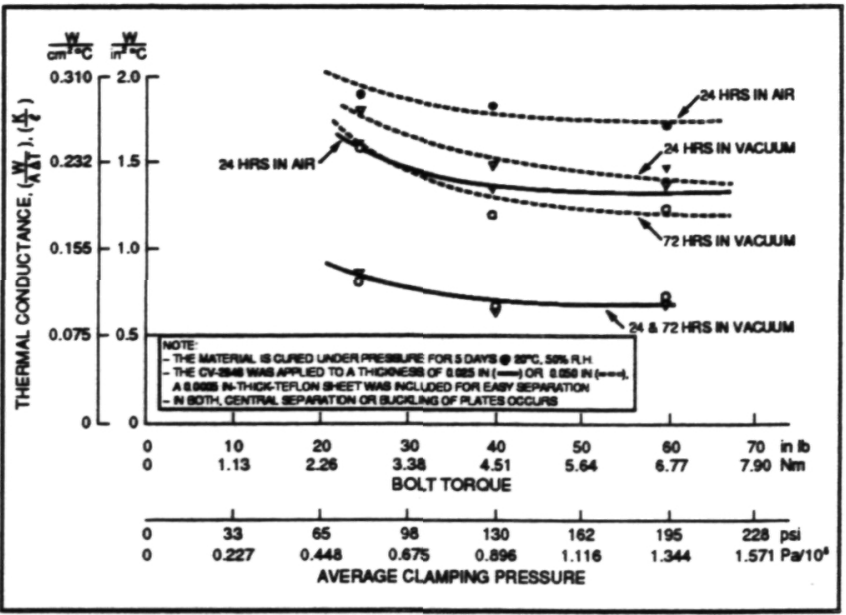

Fig. 13. Thermal conductance of $\ell=0.025$-in-thick and $\ell=0.050$-in-thick McGhan Nusil 2946 within two 8.5 -in $x$ 10-in aluminum plates bolted along the 10 -in sides with a total of ten 10-32 screws in helicoils.

are also shown in Fig. 11. They indicate that the McGhanNusil in air has conductance of about $9 \mathrm{~W} / \mathrm{in}^{2}{ }^{\circ} \mathrm{C}$, which is 1.8 times the conductance provided when the sheet is included. After 24 hours and longer in vacuum, the conductance is about $8 \mathrm{~W} / \mathrm{in}^{2}{ }^{\circ} \mathrm{C}$ or two times that with the sheet. Figure 7 shows the three-dimensional interface thickness between the twoplates with the 0.025 -in McGhan-Nusil, bolted to a torque of $\mathbf{4 0} \mathrm{in} \mathrm{lb}$. The quasi-uniformity and small buckling justify the minimal variation of conductance with pressures.

Several measurements, all including the 0.5 -mil Teflon sheet, were carried out using the $81 / 2$-in $\times 10$-in assembly with results at great variance from those with the 5- $x$ 5-in plate assembly. The measured results with the 0.025 -in thickness of McGhan Nusil as shown in Fig. 13, indicated conductance approximately 32 percent of that from the 5- x 5-in assembly in air, while conductance values were about 18 percent of those measured with the 5- $x 5$-in plate in vacuum. On separating the plates in those cases, it was apparent that the McGhan Nusil thickness varied along the plate surface. The three-dimensional plot of the McGhan Nusil thickness for

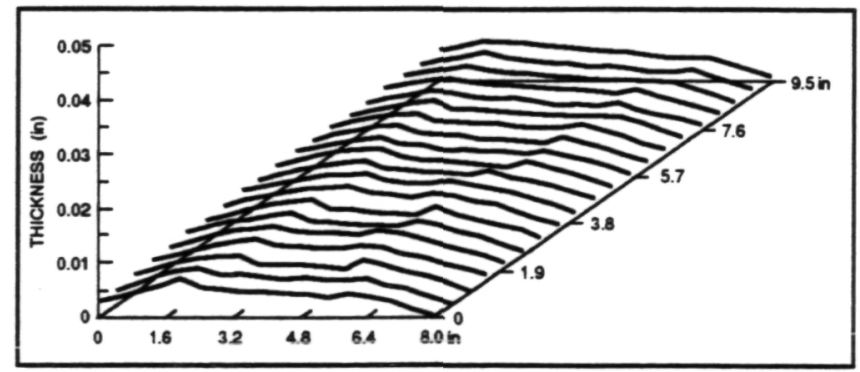

Fig. 14. Thickness map of McGhan Nusil CV-2946 applied to a thickness of 0.025 in and clamped in the 8.5-in $\times 10$-in plate assembly with bolts torqued to 25 in $\mathrm{lb}(\sim 18 \mathrm{psi}$ avg. pressure).

that case is shown in Fig. 14. It shows the depression at the center of the assembly and therefore the void created there by lack of material. As shown, the movement of the McGhanNusil on squeezing the plates at the edges leaves the central 


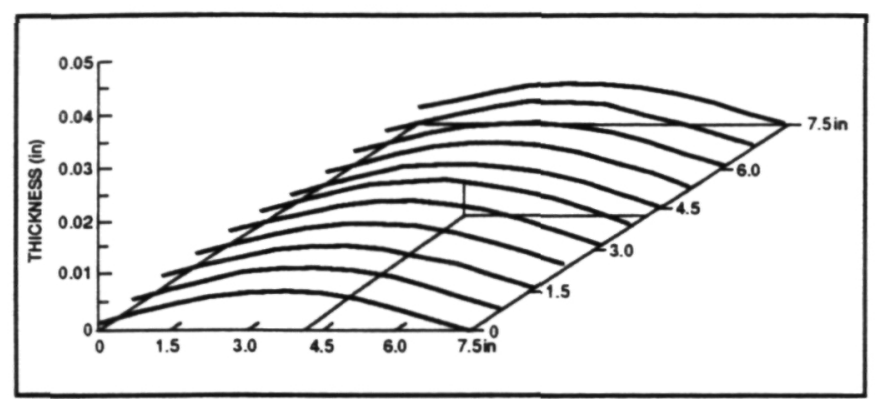

Fig. 15. Thickness map of McGhan Nusil CV-2946 applied to a thickness of 0.050 in and clamped in the 8.5-in $\times 10$-in plate assembly with bolts torqued to 40 in $\mathrm{lb}(130 \mathrm{psi}$ avg. pressure).

part with a thin film vs. a much thicker film of Nusil on the rest of the plate. The arbitrary choice of locating four of the eight sets of thermocouples at the center of the plates where voids existed provided results indicating the low conductivity and the thermal conductance deficiency at those locations. As a result, the McGhan Nusil material was doubled from 25 to 50 mil to ensure full thickness and better spread of the material. The results of the tests using the 0.050 -in thickness are shown superposed on those for the 0.025-in thickness in Fig. 13. They show an improvement of the conductance from $1.6 \mathrm{~W} /$ in $^{2}{ }^{\circ} \mathrm{C}$ to about $1.95 \mathrm{~W} / \mathrm{in}^{2}{ }^{\circ} \mathrm{C}$ in air and corresponding increases for the other conditions. However, this does not eliminate the buckling and bowing at the center of the assembly as shown by the three-dimensional measurement of the plot of Fig. 15. The deficiency of the arrangement is still evident and the results for the conductance and conductivity are only valid for this case. The results from the 5- $x$-in assembly should be used for the design thermal value of the McGhan Nusil and those from the $81 / 2$-in x 10-in assembly are to be considered valid only for that particular assembly.

\section{Conclusions and Results}

Tests have been carried out to obtain the thermal properties of two interface thermal materials for different application configurations and surrounding exposures. The two interface materials are the Cho-Therm 1671 with a nominal thickness of 0.015-in and the McGhan Nusil CV-2946 compound. The McGhan Nusil is spread on one of the interface plates. The assembly is bolted to the desired torque and the compound is allowed to cure for 3-5 days. The spread thickness of the Nusil used here was 0.025 or 0.050 in. A normally used 0.0005-in-thick Teflon sheet was included with the McGhan Nusil to provide easy joint disassembly. Tests without the Teflon sheet were also carried out for comparison. Two test configurations were used: 1 ) an assembly consisting of a 5 -in $\times 5$-in-thick Cu plate bolted to a 5 -in $\times 5$-in-thick $\mathrm{Al}$ plate with twelve 1/4-20 bolts evenly distributed along the four sides, and 2) an assembly simulating an actual space application consisting of two aluminum plates measuring $81 / 2$ in $x 10$ in with the plate on the cooling side being 0.625 in thick and the other plate being 0.19 in thick. The two plates in the 8-1/2-in x 10-in assembly were bolted together with ten
10-32 bolts evenly located along only the 10 -in sides of the plates. The input power was varied to provide a maximum total power input of $100 \mathrm{~W}$ for the 5- $x$ 5-in assembly and 595 $\mathrm{W}$ for the $81 / 2$-in $\times 10$-in assembly. The torques were varied from 15 to $70 \mathrm{in} \mathrm{lb}$ to induce average clamping pressures between 100 to $700 \mathrm{psi}$ for the 5- x 5-in assembly and pressures of 30 to $230 \mathrm{psi}$ for the 8-1/2-in x 10-in assembly. The measurements of thermal conductance were made with those conditions of pressures and powers and at normal pressure and temperature for 24 hours in air, and after 24 and 72 hours in vacuum. The thermal properties of these two interface materials may be taken as those obtained using the $5-x 5$-in assembly. That assembly is bolted with rigid, straight plates that did not distort or bow when torqued at the edges. The torques provide quasi-uniform clamping pressure throughout the plates. On the other end, for the application simulating an actual design with considerable unbolted portions on the plates and a less-than-rigid simulating cover plate, the cover plate bowed under heavy torques, allowing separation and spacing for much of the plates' area. The separation caused considerable degradation of the conductance and the values obtained here are to be considered valid only for that arrangement. Nevertheless, the tests show the importance of proper bolting and design of the assembly. Accordingly, the thermal conductances, defined as the power transmitted per unit area when a gradient of 1 degree exists across the thickness of the material $\left(\mathrm{W} / \mathrm{cm}^{2}{ }^{\circ} \mathrm{C}\right)$ are as follows:

- The maximum conductance for the Cho-Therm 1671 at normal temperature and pressure has been found to be 4.3 $\mathrm{W} / \mathrm{in}^{2}{ }^{\circ} \mathrm{C}$ when the clamping pressure is an optimum of about $200 \mathrm{psi}$ and the input power density varies up to 7 $\mathrm{W} / \mathrm{in}^{2}$. The conductance is lower at clamping pressures other than about $200 \mathrm{psi}$. At $700 \mathrm{psi}$ and for the same conditions, the conductance is about $3.5 \mathrm{~W} / \mathrm{in}^{2}{ }^{\circ} \mathrm{C}$. The conductance drops when the system is in vacuum. After 72 hours in vacuum, the conductance reaches a quasisteady value of $3.4 \mathrm{~W} / \mathrm{in}^{2}{ }^{\circ} \mathrm{C}$, becoming almost independent of the applied pressure. The degradation as a function of time in vacuum is also indicated.

The maximum conductance for the same material when used with the $81 / 2$-in $\times 10$-in arrangement at about 50 psi average clamping pressure was found to be 0.75 at normal ambient condition, and $0.3 \mathrm{~W} / \mathrm{in}^{2}{ }^{\circ} \mathrm{C}$ after 72 hours in vacuum. The explanation for this large drop is found in the large separation between the plates in the central region of the assembly when torques are applied to the bolts at the edges of the plates.

- The maximum conductance of the McGhan Nusil CV2946 compound initially spread to a thickness of 0.025 in was found to be $5 \mathrm{~W} / \mathrm{in}^{2}{ }^{\circ} \mathrm{C}$ in air with an average clamping pressure of about $350 \mathrm{psi}$ and with the 0.5 -mil Teflon included. The same conductance drops to about 4 $\mathrm{W} / \mathrm{in}^{2}{ }^{\circ} \mathrm{C}$ after 24 and 72 hours in vacuum. The same conductances are two times as high when the Teflon is omitted. Changing the clamping pressure minimally 
affects the conductance. The conductance of this material when used in the $81 / 2$-in $\times 10$-in arrangement (including the Teflon sheet) is about 1.6 at about $80 \mathrm{psi}$ in air and is about 0.8 after 24 hours or longer in vacuum. Increasing the layer thickness of the spread McGhan Nusil from 0.25 to 0.50 in provided, as expected, some improvements in conductance, since the space between the plates was filled. The conductance in that case increased from 1.6 to 1.95 , and after 72 hours in vacuum, it increased to 1.6 from $0.8 \mathrm{~W} / \mathrm{in}^{2}{ }^{\circ} \mathrm{C}$.

- Comparing the test results, one finds that the McGhan Nusil provides high conductances in air and in vacuum and is less affected by the clamping pressures than the Cho-Therm. On the other hand, the application of the Nusil is more laborious since it involves preparing the compound, applying it to the plate surface, and allowing for the curing process. Also, if separation and unbolting of the plates is needed, it is difficult to carry it out without having included in the assembly a Teflon separation sheet.

- It is obvious from these tests that for optimal thermal conductance, the interface material should be under uniform pressures over their entire surface areas. The location of the bolts, their number, their sizes and the uniformity of applied torques are all important considerations.

In conclusion, the thermal conductances of the ChoTherm 1671 and Nusil CV-2946 have been measured as a function of the clamping pressures, of the input power density, of the time in air and in vacuum, and of plate assembly design. Those properties have been measured for a quasi-rigid assembly and for a particular plate configuration simulating a space application.
Table 1 Conversions

\begin{tabular}{|c|c|}
\hline Conductance & $\begin{array}{l}1 \mathrm{Btu} / \mathrm{hr} . \mathrm{ft}^{2}{ }^{\circ} \mathrm{F}=5.67 \times 10^{-4} \mathrm{~W} / \mathrm{cm}^{2}{ }^{\circ} \mathrm{C} \\
=3.66 \times 10^{-3} \mathrm{~W} / \mathrm{in}^{2}{ }^{\circ} \mathrm{C}\end{array}$ \\
\hline Torque & 1 in $\mathrm{lb}=1.13 \times 10^{-1} \mathrm{Nm}$ \\
\hline Pressure & $\begin{array}{l}1 \mathrm{psi}=6.897 \times 10^{3} \mathrm{~Pa}=51.7 \text { torr }=2.04 \\
\text { in } \mathrm{Hg} \text {. }\end{array}$ \\
\hline Conductivity & 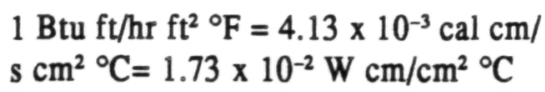 \\
\hline
\end{tabular}

\section{Acknowledgements}

The authors wish to express their gratitude to personnel of the Thermal Engineering Branch at NASA-Goddard, and in particular, Mr. N. Ackerman and Mr. R. Hoffman, who suggested the investigation.

\section{References}

'Lapinski, Jr., J.R. and Ousley, Jr., G.W. "Thermal Grease Replacement for the Modular Power System," AIAA-90-1682, Seattle, WA, May 1990.

${ }^{2}$ Chomerics Brochure 16M 589-25OR, 1988.

${ }^{3}$ Chomerics Brochures 5MA and DC382, and Bulletin 45.

${ }^{4}$ McGhan Nusil Product Profile - CV2946. 
Public reporting burden for this collection of information is estimated to averape 1 hour per response, including the time for reviewing instructions, searching existing data sources, gathering and maintaining the data needed, and completing and reviewing the collection of information. Send comments regarding this burden estimate or any other aspect of this collection of information, including suggestions for reducing this burden, to Washington Headquarters Services, Directorate for information Operations and Reports, 1215 Jefferson Davis Highway, Suite 1204. Arlington, VA 22202-4302, and to the Otfice of Management and Budger. Paperwork Reduction Project (0704-0188), Washington, DC 20503,

1204. Arlington, VA $22202-4302$, and to the Office of Management and Budget, Papenwork Reduction Project (0704-0188), Washington, $D C 20503$.
\begin{tabular}{l|l|l|} 
1. AGENCY USE ONLY (Leave blank) & 2. REPORT DATE & 3. REPORT TYPE AND DATES COVERED
\end{tabular}

\begin{tabular}{l|l|l} 
March 1992 & Technical Memorandum \\
\hline
\end{tabular}

4. TITLE AND SUBTITLE

Thermal Conductance of Two Interface Materials

and Their Applications in Space Systems

\section{FUNDING NUMBERS}

\section{AUTHOR(S)}

J.J. Scialdone, C.H. Clatterbuck, and J.L. Wall

7. PERFORMING ORGANIZATION NAME(S) AND ADDRESS(ES)

NASA-Goddard Space Flight Center

Greenbelt, Maryland 20771

\section{PERFORMING ORGANIZATION} REPORT NUMBER

$92 \mathrm{~B} 00012$

9. SPONSORING/MONITORING AGENCY NAME(S) AND ADDRESS(ES)

National Aeronautics and Space Administration

Washington, D.C. 20546-0001

10. SPONSORING/MONITORING AGENCY REPORT NUMBER

TM 104554

\section{SUPPLEMENTARY NOTES}

J.J. Scialdone, C.H. Clatterbuck, and J.L. Wall: NASA-GSFC, Code 313, Greenbelt, Maryland 20771.

12a. DISTRIBUTION/AVAILABILITY STATEMENT

Unclassified - Unlimited

Subject Category 27 12b. DISTRIBUTION CODE

\section{ABSTRACT (Maximum 200 words)}

The temperature control of spacecraft and instrument systems and subsystems requires heat transfer interface materials that possess appropriate thermal and structural characteristics, in addition to many other properties, to respond to the unique vacuum environment of space. These materials must be easy to apply to, and remove from, the surfaces where they are applied, and must be able to withstand power dissipation extremes, and be used for different clamping configurations and pressures. Silicone-based greases, used in the past, tend to migrate and to contaminate nearby surfaces. Bare metal-to-metal contact offers low thermal conductance and difficulties in estimating the actual heat transfer. Several polymeric materials containing different thermal conductive compounds and structural reinforcements have been prepared to overcome grease and metals problems.

We have evaluated two polymeric materials--the Cho-Therm 1671 elastomer, manufactured by Chomeric, Inc.; and the CV2946, a conductive RTV silicone manufactured by McGhan Nusil. Tests have been carried out to learn more about these products: one test configuration was a tightly bolted application; the other test configuration attempted to simulate heat dissipation from a modular power system of a spacecraft. Both were conducted in vacuum and in air, for many clamping pressures, power densities, and as a function of time. Results indicate that the tightly bolted, torqued fixtures (with nearly uniform clamping pressure) did not buckle or distort, and provided optimum thermal conductance. The fixtures simulating actual spacecraft configuration (with sizeable unbolted portions) suffered severe bowing and separating. This caused considerable degradation of conductance values.

\section{SUBJECT TERMS}

thermal conductance, interface material, temperature control, material thermal properties
15. NUMBER OF PAGES

12

16. PRICE CODE

\begin{tabular}{|l|c|c|c|}
\hline $\begin{array}{l}\text { 17. SECURITY CLASSIFICATION } \\
\text { OF REPORT } \\
\text { Unclassified }\end{array}$ & $\begin{array}{c}\text { 18. SECURITY CLASSIFICATION } \\
\text { OF THIS PAGE } \\
\text { Unclassified }\end{array}$ & $\begin{array}{l}\text { 19. SECURITY CLASSIFICATION } \\
\text { OF ABSTRACT } \\
\text { Unclassified }\end{array}$ \\
\hline
\end{tabular}

20. UMITATION OF ABSTRACT 
National Aeronautics and

Space Administration

Washington, D.C.

20546

Official Business

Penalty for Private Use, $\$ 300$
Postage and Fees Paid

National Aeronautics and

Space Administration

NASA-451

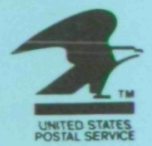

